\title{
Civil Turbofan Engine Exhaust Aerodynamics: Impact of Bypass Nozzle After-body Design
}

\author{
loannis Goulos; \\ Tomasz Stankowski, David MacManus \\ Propulsion Engineering Centre \\ School of Aerospace, Transport and Manufacturing \\ Cranfield University \\ Bedfordshire, MK43 OAL, UK
}

\author{
Philip Woodrow, Christopher Sheaf \\ Installation Aerodynamics \\ Rolls-Royce plc \\ Derby , DE24 8BJ, UK
}

\begin{abstract}
It is envisaged that the next generation of civil large turbofan engines will be designed for greater bypass ratios when compared to contemporary architectures. The underlying motivation is to reduce specific thrust and improve propulsive efficiency. Concurrently, the aerodynamic performance of the exhaust system is anticipated to play a key role in the success of future engine architectures. The transonic flow topology downstream of the bypass nozzle can be significantly influenced by the after-body geometry. This behavior is further complicated by the existence of the air-flow vent on the nozzle after-body which can have an impact on the performance of the exhaust system. This paper aims to investigate the aerodynamics associated with the geometry of the bypass nozzle after-body and to establish guidelines for the design of separate-jet exhausts with respect to future large turbofan engines. A parametric geometry definition has been derived based on Class-Shape Transformation (CST) functions for the representation of post-nozzle-exit components such as after-bodies, plugs, and air-flow vents. The developed method has been coupled with an automatic mesh generation and a Reynolds Averaged Navier-Stokes (RANS) flow solution method, thus devising an integrated aerodynamic design tool. A cost-effective optimization strategy has been implemented consisting of methods for Design Space Exploration (DSE), Response Surface Modeling (RSM), and Genetic Algorithms (GAs).

The combined approach has been deployed to explore the aerodynamic design space associated with the bypass nozzle after-body geometry for a Very High Bypass Ratio (VHBR) turbofan engine with separate-jet exhausts. A detailed investigation has been carried out to expose the transonic flow mechanisms associated with the effect of after-body curvature combined with the
\end{abstract}

\footnotetext{
${ }^{*}$ Corresponding and lead author, Building 52, Room 233, Cranfield University, E: i.goulos@cranfield.ac.uk, T: +44 (0) 1234754648
}

impact of the air-flow vent. A set of optimum curved after-body geometries has been obtained, with each subsequently compared against their respective conical representation. The obtained results suggest that no significant performance improvements can be obtained through curving the nozzle after-body relative to the case of a conical design. However, it is shown that the application of surface curvature has the potential to unlock new parts in the design space that allow analysts to reduce the required after-body length without any loss in aerodynamic performance. The developed approach complements the existing tool-set of enabling technologies for the design and optimization of future large aero-engines, consequently leading to increased thrust and reduced Specific Fuel Consumption (SFC).

Keywords: Turbofan engine aerodynamics, Computational fluid dynamics, Propulsion integration, Class-shape transformation functions, Exhaust nozzles, Annular after-bodies, Design optimization, Transonic flow aerodynamics

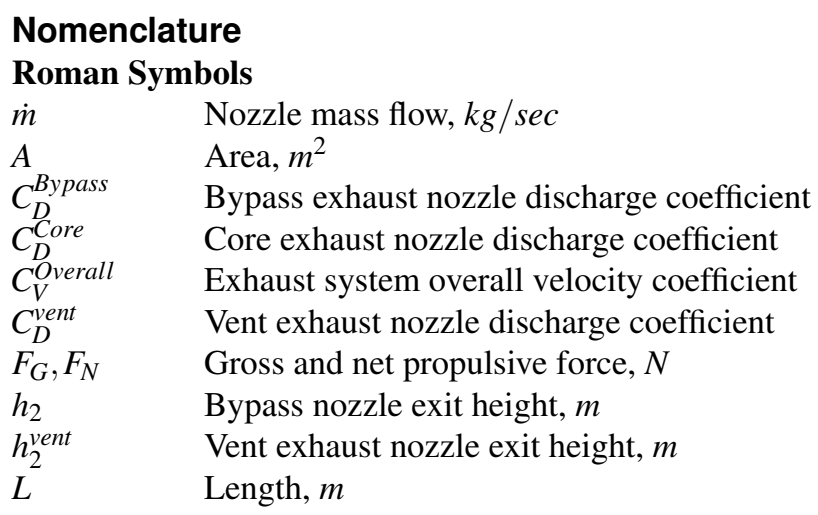

I. Goulos et al. 


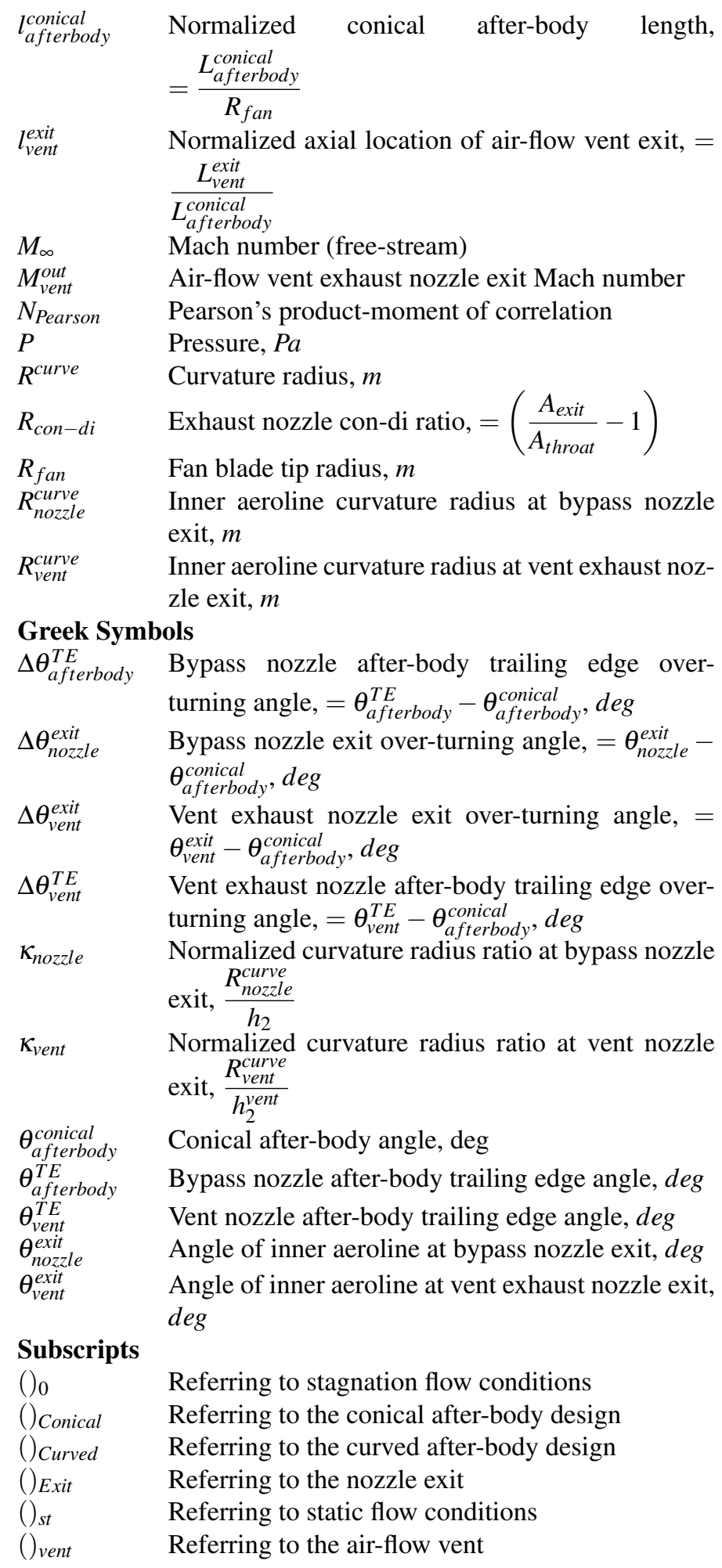

\section{Introduction}

\subsection{Background}

Current design trends for civil turbofan engines dictate continuously lowering specific thrust to improve propulsive efficiency and reduce Specific Fuel Consumption (SFC) [1]. This is done by lowering the Fan Pressure Ratio (FPR) and increasing the engine By-Pass Ratio $\left(B P R=\frac{\dot{m}_{\text {bypass }}}{\dot{m}_{\text {core }}}\right)$ which results in a higher-amount of mass flow exhausted through the bypass nozzle $\dot{m}_{\text {bypass }}$, relative to the core engine flow $\dot{m}_{\text {core }}$. Due to the large ratio of gross to net propulsive force $\frac{F_{G}}{F_{N}}$ associated with the next generation of civil aero-engines [2], small variations in the aerodynamic behavior of the exhaust system may have detrimental impact on overall engine performance [3]. Consequently, the aerodynamic design of the exhaust system is key to the success of future engine architectures.

Medium to large civil turbofan engines usually employ some variation of a separate-jet exhaust system as opposed to mixed nozzles. An illustration of an axi-symmetric engine geometry equipped with a separate-jet exhaust system is presented in Fig. 1. Within the context of this work, the term "exhaust system" refers to the bypass and core ducts and nozzles, as well as any post-exit components located downstream of the nozzle exits. The bypass and core flows are separated by the bypass nozzle after-body, also referred to as the "core after-body". The bypass and core streams meet and mix downstream of the core nozzle exit. An air-flow vent is usually located on the core after-body and is used to exhaust secondary air-flows from the engine core. A protruding core plug is employed to reduce the core after-body length required for a given core nozzle exit area.

The gross propulsive force $F_{G}$ produced by the exhaust system can be substantially influenced by the aerodynamic pressure and viscous forces exerted on the walls of the bypass duct and nozzle, core after-body, and protruding core plug. Dusa et al. [4] reported that for high-bypass ratio turbofan engines, the gross thrust loss due to non-isentropic flow conditions can be of the order of $1.5-2.0 \%$ relative to the ideal case of fully-expanded isentropic flow. To establish a standard accounting process, it is common practice to compare the actual nozzle performance with that of an ideal nozzle through the definition of the nondimensional discharge and velocity coefficients, $C_{D}$ and $C_{V}$, respectively $[5,6]$. Thus, from a design perspective, it is desirable that the geometry of the exhaust system is optimized to ensure the maximum aerodynamic performance in terms of $C_{D}$ and $C_{V}$.

The concept of exhaust design optimization for civil aeroengines has been formerly tackled by Goulos et al. [7, 8]. However, previous work done on the topic by the authors $[7,8]$ as well as other researchers, [9-11], has been based on the implicit assumption of a simplified conical representation for the exhaust components located downstream of the bypass nozzle, such as the core after-body and plug (Fig. 1). However, the resultant tran-

I. Goulos et al. 


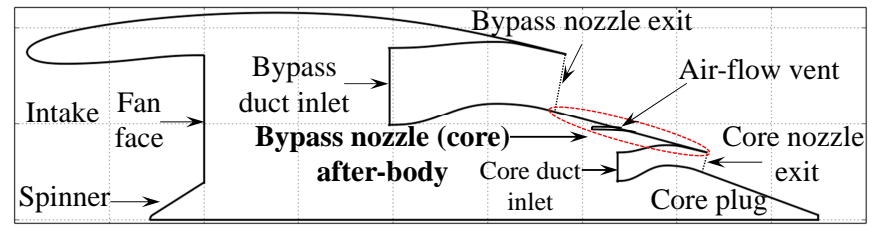

Figure 1. Example axi-symmetric housing geometry for a civil gasturbine aero-engine with separate-jet exhausts

sonic flow topology downstream of the bypass exhaust nozzle can be significantly influenced by the after-body curvature [12]. This behavior is further complicated by the existence of the airflow vent on the core after-body (Fig. 1) which can have an impact on the aerodynamics of the exhaust system and, inevitably, on overall SFC. Hence, it is essential that the aerodynamic impact of after-body curvature is meticulously explored to enable the global optimization of the exhaust system.

\subsection{Aerodynamic design of nozzle after-bodies}

The literature available in the public domain covering the aerodynamic design of exhaust nozzles, after-bodies, and plugs is relatively scarce. Furthermore, it is predominantly founded on grounds of experimental testing done on single-stream exhaust nozzles with conical or circular-arc after-bodies.

The Engineering Sciences Data Unit (ESDU) published an empirical method for the estimation of subsonic pressure drag coefficients of after-bodies with central propulsive jets [13,14]. The ESDU method is based on a series of prediction procedures for the base, boat-tail, and total after-body pressure drag coefficients of single-stream nozzles. Available design parameters include the boat-tail angle, nozzle exit diameter, base area, and maximum nozzle diameter. However, the ESDU method is not able to predict actual nozzle performance in terms of discharge or velocity coefficients. Furthermore, it is only applicable to axisymmetric exhausts with circular-arc or similar boat-tails fitted with convergent or parallel single-stream nozzles without plugs.

Compton [15-17] and Compton and Runckel [18] performed an extensive campaign of experimental investigations on the aerodynamic behavior of single-stream jet exhausts for turbojet engines with conical after-bodies. The effect of nozzle exit base recession as a means of reducing base pressure drag was reviewed in Ref. [17]. A series of different designs were investigated experimentally, such as; flat, concave, open, and semitoroidal concave. It was concluded that increasing base concavity may have a favorable effect on base pressure up to a threshold depending on nozzle boat-tail angle.

Peace [12] developed a numerical approach for the estimation of viscous and compressible flows around single-stream as well as co-axial exhaust nozzles and after-bodies. The bulk aerodynamic analysis was carried out using an inviscid and compressible Euler flow-solver [19]. The baseline method was modified to include viscous effects due to boundary-layers on the after-body walls and shear-layers in the jet wake using the formu- lation developed by Williams [20]. The combined method was deployed to investigate the aerodynamic behavior of "circulararc-type" as well as conical after-bodies for single-stream nozzles and co-axial jet exhausts, respectively. Numerical predictions were compared with experimental measurements in terms of static pressure distributions on the after-body surfaces. Peace noted that for coaxial jets, reasonably good agreement is obtained when the nozzles operate un-choked. The observed agreement seemed to deteriorate for the choked-nozzle cases where a strong adverse shock topology may manifest on the core after-body.

\subsection{Scope of present work}

In light of the aforementioned context, this paper aims to develop a holistic approach for the Design Space Exploration (DSE) and optimization of conceptual separate-jet exhaust systems for the next generation of civil aero-engines. The developed method extends previous work done by the authors on the topic $[7,8]$ through the implementation of a parametric geometry definition for the post-nozzle-exit components. The proposed method inherits the intuitiveness and flexibility of Class-Shape Transformation (CST) functions originally developed for airfoil parameterization [21-23], and extends their applicability to the representation of nozzle after-bodies, plugs, and air-flow vents. The combined approach has been coupled with an automatic mesh generation and a RANS flow solution method, thus formulating an integrated aerodynamic design tool. A computationally efficient optimization strategy has been developed comprising methods for Design Of Experiment (DOE), Response Surface Modeling (RSM), as well as Genetic Algorithms (GAs).

Within this work, the computational framework previously developed $[7,8]$ has been applied to explore the exhaust design space of a VHBR turbofan, representative of the next generation of civil large aero-engines. The effect of after-body surface curvature and air-flow vent design on the aerodynamic behavior of a separate-jet exhaust system has been investigated. The transonic flow mechanisms that influence the aerodynamic performance of separate-jet exhaust after-bodies have been determined. A series of optimum curved after-body designs have been obtained and compared against their respective conical baselines to assess the aerodynamic benefit associated with the effect of after-body curvature. Furthermore, an attempt has been made to arrive to a definitive remark considering the influence of after-body curvature that is applicable throughout the global design space including all air-flow vent positions and exit area requirements.

\section{Methodology}

This work aims to adapt and expand the capability of the computational framework previously developed by Goulos $e t$ al. $[7,8]$ for the aerodynamic design of civil aero-engines with separate-jet exhausts. The employed tool has been named GEMINI (Geometric Engine Modeler Including Nozzle Installation). GEMINI encompasses a series of fundamental modeling meth- 
ods originally developed for: engine performance analysis [24], exhaust duct and nozzle aeroline parameterization [7, 21-23], viscous-compressible flow solution [25,26], as well as DSE and Multi-Objective Optimization (MOO) [8].

\subsection{GEMINI: Exhaust system aerodynamic design}

GEMINI initiates the design process based on a userprescribed set of engine cycle and geometric design parameters. The aero-thermal behavior of the employed cycle is evaluated for a series of key operating points within the operational envelope of interest. The required aero-thermal analysis is carried out using the zero-dimensional (0D) engine performance simulation tool Turbomatch [27] originally developed by Macmillan [24]. The purpose of this process is two-fold: (a) It determines the flow-capacity requirements for the bypass and core exhaust nozzles, and (b) It establishes boundary conditions for the flow properties at the inlet of the bypass and core exhaust nozzles (Fig. 1).

Having determined the required nozzle flow-capacities, GEMINI applies an inverse design approach to derive a $2 \mathrm{D}$ axisymmetric representation of the aerodynamic lines for the bypass and core nozzles, including their downstream after-bodies (Fig. 1). An automatic mesh generation tool is subsequently deployed to compute the axi-symmetric, multi-block, structured grid [25] for the engine geometry including the separate-jet exhaust system. Hence, among others, GEMINI establishes the Computational Fluid Dynamics (CFD) domain upon which the viscous and compressible flow-field can be resolved.

The flow solver ANSYS Fluent [26] is employed as the current aerodynamic analysis method. Computations are carried out using a RANS CFD approach coupled the $k-\omega$ Shear-Stress Transport (SST) turbulence model [28]. The Green-Gauss node based method is used for calculation of the flow-field gradients. A second-order accurate upwind scheme is used for the spatial discretization of primitive variables as well as turbulent kinetic energy $k$ and specific dissipation rate $\omega$. Thermal conductivity $(\kappa)$ is computed according to kinetic theory. Variable gas properties are employed using an $8^{\text {th }}$ order polynomial expression for the calculation of specific heat capacity as a function of static temperature [26]. The calculation of dynamic viscosity is carried out based on Sutherland's law [26]. Bardina et al. [29] showed that the $k-\omega$ SST model can moderately over-predict the onset and amount of flow separation under the influence of an adverse pressure gradient. Thus, the employed CFD approach is expected to provide conservative estimates of aerodynamic performance with regards to design regions where flow-separation may occur.

Having obtained a converged flow solution, the numerical data are automatically post-processed to determine the exhaust system's performance metrics of interest. These include the bypass and core nozzle discharge coefficients, $C_{D}^{\text {Bypass }}$ and $C_{D}^{\text {Core }}$, respectively, as well as the overall exhaust system velocity coefficient $C_{V}^{\text {Overall }}$ [7]. The CFD methods and approach employed in GEMINI have been verified and validated by Goulos et al. [7].

\subsection{Exhaust nozzle design and analysis}

GEMINI incorporates a parametric geometry definition based on the Class-Shape function Transformation (CST) method originally proposed by Kulfan [21,22] and further developed by Qin [23]. The employed approach developed by Goulos et al. [7] inherits the intuitiveness and flexibility of Qin's CST variation [23] and extends its applicability to the parametric representation of exhaust ducts and nozzles. The adapted formulation allows to express the bypass/core duct, nacelle exhaust, and after-body aerolines as functions of intuitive parameters [7].

\subsection{Parametric geometry definition of axi-symmetric exhaust nozzle after-bodies}

To investigate the aerodynamic behavior of the bypass nozzle after-body, a suitable parametric geometry definition is required. The employed approach has to be flexible and allow sufficient generality to explore a wide-range of geometries without over-constraining the design space. Furthermore, the required design flexibility has to be satisfied using a small number of Degrees of Freedom (DOFs), also referred to as "design variables". The underlying necessity is to mitigate the so-called "curse of dimensionality" [30] which can manifest when analyzing multidimensional spaces with a high number of design variables.

At this point, it is clarified that the nature of the present DSE approach requires to limit the dimensionality of the design space in order to maintain an acceptable accuracy of RSM approximation to be used for subsequent optimizations. However, the exploration of high-dimensional aerodynamic design spaces has been enabled with the advent of the discrete adjoint compressible RANS formulation [31].Specifically, Heath et al. [9] were able to apply a non-linear gradient-based optimization approach coupled with the discrete adjoint formulation of the RANS equations for the shape optimization of a dual-stream plug nozzle using up to 20 design variables. Thus, gradient-based optimization methods have been shown to cope adequately with high-dimensional spaces in the context of aerodynamic shape optimization.

Within this work, the CST variation developed by Goulos et al. [7] for the parametric geometry definition of exhaust ducts and nozzles, is extended to the design of after-bodies. Figure 2 demonstrates the parametric geometry definition used to establish a generalized representation for the bypass nozzle after-body. The topology of a datum exhaust featuring a simplified conical after-body with half-cone angle $\theta_{\text {afterbody }}^{\text {conical }}$, is shown in Fig. 2(a). It can be noted that the overall after-body geometry comprises two main components: (a) The part located upstream of the airflow vent and (b) the part positioned downstream of the air-flow vent. The employed approach allows to control the curvature parameters of each part independently. The design variables controlling the curvature of each component are shown in Figs. 2(b) and (c) for the upstream and downstream sections, respectively.

Figures 2(b) and (c) demonstrate that a total of three (3) variables are incorporated to control the surface curvature for each 
after-body section. With respect to the after-body portion located upstream of the air-flow vent, Fig. 2(b) shows that the selected design variables can be outlined as follows: (a) the bypass nozzle inner annulus exit angle $\theta_{\text {nozzle }}^{\text {exit }}$ which controls the angle of the inner aeroline at the nozzle exit, (b) the bypass nozzle inner annulus exit curvature radius $R_{\text {nozzle }}^{\text {curve }}$ which defines a finite inner line radius of curvature at the nozzle exit, and (c) the after-body Trailing Edge (TE) angle $\theta_{\text {afterbody }}^{T E}$. The datum conical afterbody geometry with half-cone angle $\theta_{\text {afterbody }}^{\text {conical }}$ is also shown using a grey dashed line. To establish an intuitive representation of the curved after-body geometry, the identified design variables are related to the corresponding conical geometry as follows:

$$
\begin{array}{r}
\Delta \theta_{\text {nozzle }}^{\text {exit }}=\theta_{\text {nozzle }}^{\text {exit }}-\theta_{\text {afterbody }}^{\text {conical }} \\
\Delta \theta_{\text {afterbody }}^{T E}=\theta_{\text {afterbody }}^{T E}-\theta_{\text {afterbody }}^{\text {conical }} \\
\kappa_{\text {nozzle }}=\frac{R_{\text {nozzle }}^{\text {curve }}}{h_{2}}
\end{array}
$$

where $h_{2}$ is the bypass nozzle exit height as shown in Fig. 2(a). The same approach is applied to derive a parametric geometry definition for the after-body part located downstream of the airflow vent as demonstrated in Fig. 2(c). This results in another three (3) intuitive design variables: $\Delta \theta_{\text {vent }}^{\text {exit }}, \Delta \theta_{\text {vent }}^{T E}$, and $\kappa_{\text {vent }}$.

The parametric representation outlined above results in a total of six (6) design variables, as shown in Figs. 2(b) and (c). These can control the surface curvature with respect to both afterbody sections. As such, they can be employed to derive the associated geometric constraints that the curved after-body lines need to satisfy. The CST variation described by Goulos et. al [7] is subsequently applied using the prescribed constraints to derive the curved after-body geometry. The employed approach ensures curvature continuity throughout the entire after-body shape due to the infinitely differentiable nature of CST functions [21,22].

The proposed method can be used to design a wide-range of after-body geometries including concave, convex, and mixed convex-concave or concave-convex designs using a relatively small number of intuitive design variables. Figure 3 demonstrates the capability of the adapted formulation to capture the diversity inherent in the design space of conceptual exhaust afterbody geometries with finite curvature variations.

\subsection{Design space exploration and optimization}

To perform a thorough investigation with respect to the aerodynamic impact of after-body curvature, the Design Space Exploration (DSE) environment of GEMINI has been utilized [8]. GEMINI incorporates a robust and computationally efficient optimization strategy that accounts for the inherent non-linearity of transonic flow aerodynamics and mitigates the computational cost associated with numerous CFD simulations. The optimization strategy of GEMINI has been described in Ref. [8].

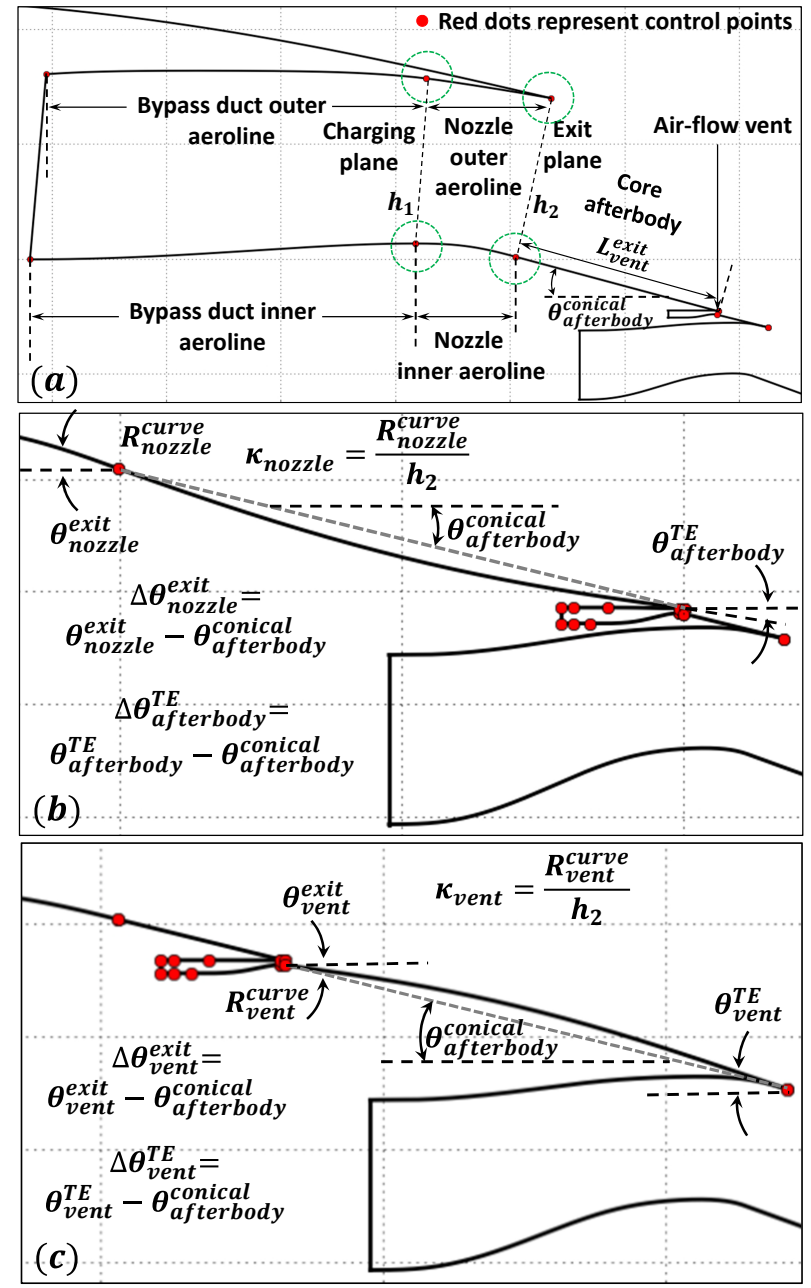

Figure 2. Parametric geometry for bypass nozzle after-body: (a) exhaust system overview, (b) after-body portion located upstream of airflow vent, (c) after-body portion located downstream of air-flow vent

The DSE environment of GEMINI consists of mathematical methods for Design Space Exploration (DSE), Response Surface Modeling (RSM - also referred to as surrogate modeling), and Multi-Objective Optimization (MOO). The DSE procedure comprises two major aspects; (a) an initial Design of Experiment (DOE) which aims to strategically populate the design space, and (b) the mathematical formulation of Response Surface Models (RSMs) using the computed DOE sample data. A DOE is a systematic approach to get the maximum amount of information out of a given number of samples. The Latin Hypercube Design (LHD) algorithm [32] has been selected for this work. Having completed the LHD DOE approach, RSMs can be subsequently structured using the obtained DOE results as model inputs. Interpolation using Gaussian Processes Regression [33] (Kriging Interpolation) has been the method of choice for this work.

The structured RSMs can subsequently be used to approximate the aerodynamic behavior of the exhaust system. GEMINI 


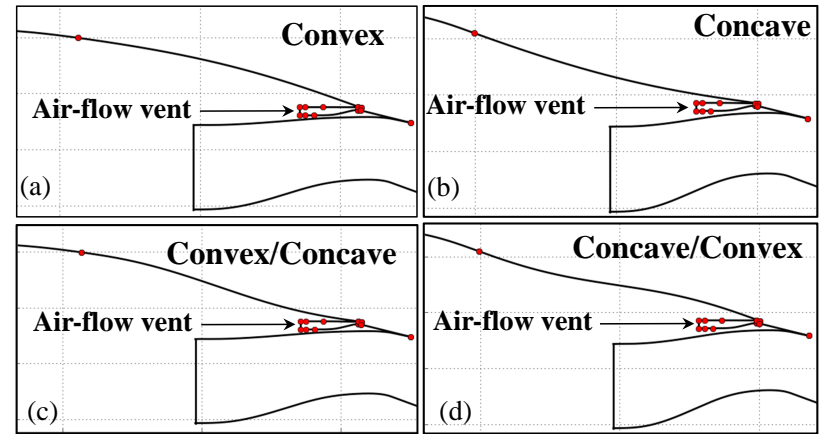

Figure 3. Example bypass nozzle after-bodies designed using the developed method including concave, convex, and mixed geometries

is based on the deployment of RSMs as drivers during the optimization process instead of using direct CFD simulations. This is done to mitigate the excessive computational cost associated with multiple CFD evaluations. The classical Leave-One-Out (LOO) cross-validation method [34] is employed to assess the predictive accuracy of the structured RSMs prior to using them in an optimization environment. After successful approximation of the simulation method's response to design inputs, the available design space can be systematically explored for optimum solutions. The employed optimization approach has to be immune to the danger of being trapped between locally optimum solutions. Hence, the deployment of a global method is required. The Nondominated Sorting Genetic Algorithm II (NSGA-II) originally proposed by Deb et al. [35] has been selected to carry out the optimizations reported in this paper.

\section{Results and discussion}

A comprehensive numerical investigation was carried out to assess the effect of bypass nozzle after-body curvature (Fig. 3) on the exhaust aerodynamics of a civil aero-engine. The baseline power-plant architecture was defined to be representative of future large turbofans. The engine cycle was structured using publicly available information [36]. The cycle parameters and component efficiencies were selected according to an estimated "year 2025 to 2030" technology level [37,38].

The geometric topology used for the datum exhaust system is illustrated in Fig. 2(a). The baseline exhaust system has been pre-optimized at design-point mid-cruise conditions using the numerical approach developed by Goulos et al. [8] assuming a conical after-body representation. Guynn et al. [36] showed that with respect to future civil aero-engines, the employed FPR at near mid-cruise conditions can range between 1.3 and 1.5 , depending on cycle architecture and $B P R$. For the the purpose of this work, an FPR of 1.4 has been selected to reflect the middle of the FPR range for a VHBR turbofan engine with $B P R \approx 16$. For $M_{\infty}=0.85$, the selected FPR value results in a bypass nozzle NPR of approximately 2.2 . The bypass and core nozzle pressure ratios, along with the free-stream conditions are also listed
Table 1. Baseline engine operating parameters

\begin{tabular}{lcc}
\hline Cycle parameter. & Value & Unit \\
\hline$\left(\frac{P_{0}^{\text {inlet }}}{P_{s t}^{\text {amb }}}\right)^{\text {Bypass }}$ & 2.2 & - \\
$\left(\frac{P_{0}^{\text {inlet }}}{P_{s t}^{\text {amb }}}\right)^{\text {Core }}$ & 1.5 & - \\
$B P R$ & 16 & - \\
$F P R$ & 1.4 & - \\
$M_{\infty}$ & 0.85 & - \\
Altitude & 10668 & $m$ \\
\hline
\end{tabular}

in Table 1 for consistency. These denote the boundary conditions specified for the aerodynamic computations presented in this paper. The derivation and analysis of the employed thermodynamic engine cycle has been further described by Goulos et al. [7].

\subsection{Aerodynamic effect of after-body surface concavity}

A parametric analysis was initially carried out to understand the fundamental aerodynamic mechanisms associated with the influence of after-body surface concavity (Fig. 3). As elaborated in section 2.3 of this paper, the after-body geometry comprises two sections: (a) The part located upstream of the air-flow vent (Fig. 2(b)) and (b) the part positioned aft of the vent nozzle exit (Fig. 2(c)). The position of the air-flow vent on the after-body can have a significant impact on the aerodynamic behavior of the exhaust system $[7,8]$. The flow exhausted through the vent is usually of low total pressure and Mach number. As such, it is sensitive to adverse pressure gradients generated by surface concavity with a high potential for flow-separation. Furthermore, the geometric "radial step" at the vent nozzle exit (Fig. 2) can alter the transonic flow topology on the after-body. Thus, depending on the vent location, different flow mechanisms may manifest and impact on the performance of the exhaust system.

To understand the sensitivity of exhaust performance with respect to the effect of after-body curvature, two baseline designs with conical after-bodies $\left(\Delta \theta_{\text {nozzle }}^{\text {exit }}=-\Delta \theta_{\text {afterbody }}^{T E}=0^{\circ}\right.$ and $\Delta \theta_{\text {vent }}^{\text {exit }}=-\Delta \theta_{\text {vent }}^{T E}=0^{\circ}$ ) were employed based on the datum configuration shown in Fig. 2(a). The sole difference between the two baseline exhaust designs is the axial location of the vent nozzle on the core after-body $l_{\text {vent }}^{\text {exit }}=\frac{L_{\text {vent }}^{\text {exit }}}{L_{\text {afterbody }}^{\text {conical }}}$, where $L_{\text {afterbody }}^{\text {conical }}$ the total after-body length from bypass nozzle exit to core nozzle exit. For the first datum exhaust geometry $(D 1)$, the vent is positioned at an aft location $\left(l_{\text {vent }}^{\text {exit }}=0.85\right)$ and in close proximity to the after-body TE and core nozzle exit. With regards to the second datum design $(D 2)$, the vent is placed upstream at $l_{\text {vent }}^{\text {exit }}=0.25$, near the vicinity of the bypass nozzle exit.

The associated flow solutions for the baseline exhaust sys- 
tems are presented in Figs 4(a) and (b) for the first (D1: $l_{\text {vent }}^{\text {exit }}=$ $0.85)$ and second $\left(D 2: l_{\text {vent }}^{\text {exit }}=0.25\right)$ case, respectively. It can be observed that for cruising flight, the bypass nozzle operates under choked conditions. As a result, a transonic flow-topology is formulated aft of the bypass nozzle exit and on the core after-body. However, due to the lower value of core Nozzle Pressure Ratio (NPR) shown in Table 1, the core nozzle operates unchoked. The vent exhaust nozzle is also unchoked and is designed for nominal exit flow Mach number of approximately 0.5. Moreover, it can be noted that for both conical after-body designs, the transonic flow-topology aft of the bypass nozzle exit comprises flow regions of relatively low supersonic Mach number $(M<1.1)$. Hence, the resultant oblique-shocks and reflected expansion fans on the after-body are relatively weak.

To assess the influence of after-body surface concavity and convexity on the aerodynamic behavior of the investigated exhaust systems, a parametric analysis was carried out for both configurations, $D 1$ and $D 2$. To bound the design space within strictly concave and convex surfaces (Figs. 3(a) and (b)), the initial and final after-body angles of the $D 1$ design were varied in a tandem and opposite manner $\left(\Delta \theta_{\text {nozzle }}^{\text {exit }}=-\Delta \theta_{\text {afterbody }}^{T E}\right)$. The nozzle exit curvature radius ratio $\kappa_{\text {nozzle }}$ was held fixed for all investigated designs. This approach ensured that the parametric analysis was focused strictly on the effect of surface concavity and convexity and that any mixed designs (Figs. 3(c) and (d)) with intermediate aeroline inflections were eliminated. The same approach was applied for the $D 2$ design where the respective geometric variables were handled in a similar fashion. Furthermore, no surface curvature was applied aft of the vent nozzle for the $D 1$ configuration (Fig. 4(a)). With respect to the $D 2$ case (Fig. 4(b)), the after-body part located upstream of the vent nozzle exit was kept conical.

Figure 5 presents the influence of after-body surface concavity on the exhaust system's aerodynamic performance. $\mathrm{Nu}-$ merical predictions are shown for the overall exhaust system velocity coefficient $C_{V}^{\text {Overall }}$ and the bypass nozzle discharge coefficient $C_{D}^{\text {Bypass }}$ regarding both architectures. Results are reported as percentage differences relative to the performance of the corresponding conical exhausts depicted in Figs. 4(a) and (b) for the $D 1$ and $D 2$ datum models, respectively. It can be immediately observed that the aerodynamically optimum design region for both $C_{V}^{\text {Overall }}$ as well as $C_{D}^{\text {Bypass }}$, is very close to a conical after-body. This observation is valid with respect to both investigated exhaust designs. Inclusion of surface concavity or convexity appears to affect the aerodynamic performance of the exhaust system in an adverse manner. This behavior can be explained by analyzing the flow solutions illustrated in Figs. 4(c)-(f).

Regarding the $D 1$ case, Fig. 4(c) shows that a concave afterbody leads to an unfavorable transonic flow topology. The afterbody flow is dominated by a strong normal shock that forms immediately aft of the bypass nozzle exit. This is due to an effective convergent-divergent (con-di) nozzle ratio $R_{\text {con-di }}=$

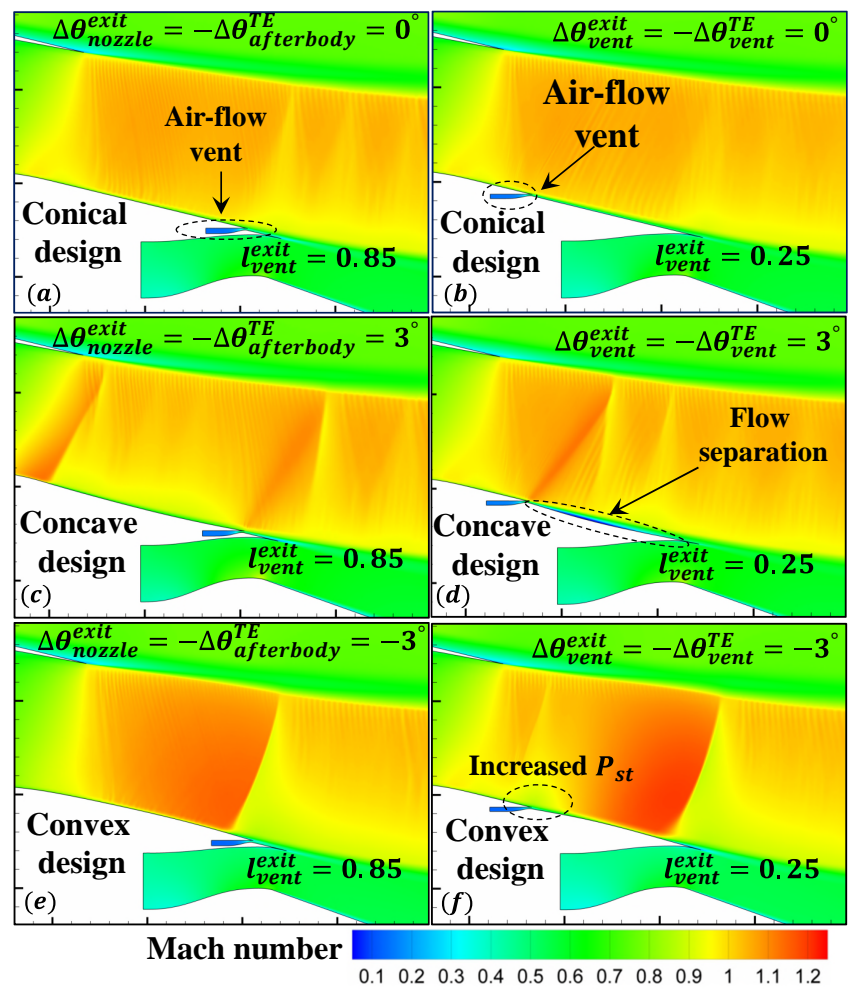

Figure 4. Exhaust after-body aerodynamics: (a) Datum conical $D 1$ design $\left(l_{\text {vent }}^{\text {exit }}=0.85\right)$, (b) Datum conical D2 design $\left(l_{\text {vent }}^{\text {exit }}=0.25\right)$, (c) Concave $D 1$, (d) Concave $D 2$, (e) Convex $D 1$, (f) Convex $D 2$

$\left(\frac{A_{\text {exit }}}{A_{\text {throat }}}-1\right)(\%)$ that manifests with increasing $\Delta \theta_{\text {nozzle }}^{\text {exit }}$. This moves the nozzle throat upstream of its exit plane leading to excessive flow acceleration which terminates with a strong normal shock. Furthermore, a second normal shock can be noted forming downstream of the after-body TE. This is due to an expansion fan triggered by the geometric step at vent exit. Both flow features reduce the exhaust system's $C_{V}^{\text {Overall }}$ as shown in Fig. 5(a).

Figure 4(e) demonstrates that a convex after-body surface can result in excessive flow acceleration downstream of the bypass nozzle exit. The supersonic bypass nozzle flow subsequently terminates with a strong normal shock that forms immediately upstream of the air-flow vent. The observed normal shock reduces the exhaust system's aerodynamic performance as shown in Fig 5(a). With respect to the convex after-body illustrated in Fig. 4(e) for which $\Delta \theta_{\text {nozzle }}^{\text {exit }}=-\Delta \theta_{\text {afterbody }}^{T E}=-3^{\circ}$, the respective value of $\Delta C_{V}^{\text {Overall }}$ is of the order of $-0.04 \%$.

Considering the $D 2$ case (Fig. 4(b)) where the vent exhaust is positioned near the vicinity of the bypass nozzle exit, Fig. 5(c) shows that a concave after-body can also affect the aerodynamics in an adverse manner. However, the flow-mechanisms are different compared to the D1 case. Specifically, Fig. 4(d) demonstrates that the surface concavity has caused the flow downstream of the air-flow vent to separate. As discussed in this section, 

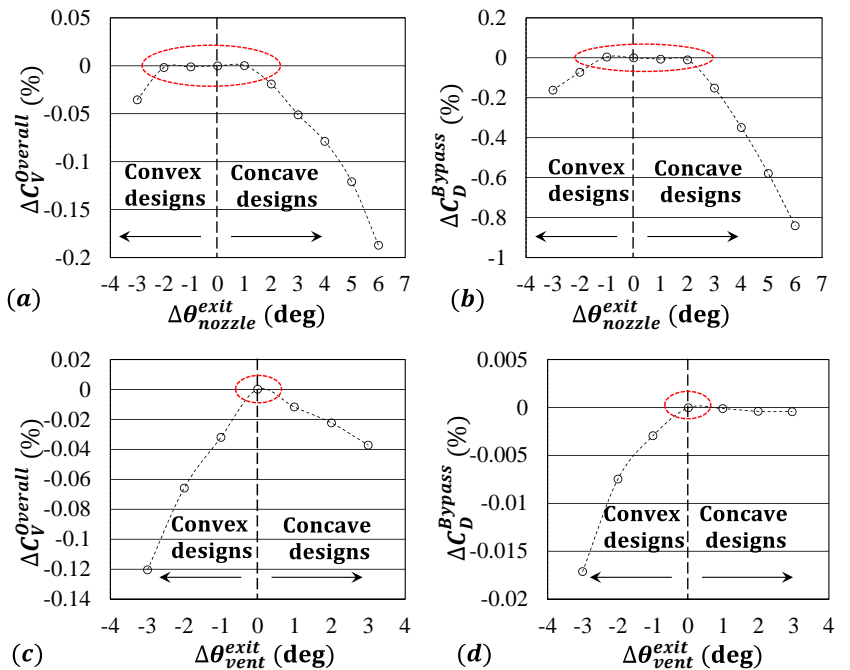

Figure 5. Effect of after-body concavity on aerodynamic performance relative to conical design: (a) $\Delta C_{V}^{\text {Overall }}$ for $D 1$ case, (b) $\Delta C_{D}^{\text {Bypass }}$ for $D 1$ case, (c) $\Delta C_{V}^{O v e r a l l}$ for $D 2$ case, (d) $\Delta C_{D}^{\text {Bypass }}$ for $D 2$ case

the flow expelled through the vent is of relatively low total pressure. Thus, it is sensitive to adverse pressure gradients that can manifest due to surface concavity. Moreover, a relatively strong oblique expansion fan can be noted that is triggered at the vent exit. The expansion fan is reflected at the stream-tube boundary as a shock wave which reduces total pressure. The combined effect of both adverse flow phenomena is a reduction in performance with $\Delta C_{V}^{O \text { verall }}$ reaching $-0.04 \%$ for $\Delta \theta_{\text {vent }}^{\text {exit }}=-\Delta \theta_{\text {vent }}^{T E}=3^{\circ}$ as shown in Fig. 5(c).

Figure 4(f) shows that the effect of after-body surface convexity is similar to that noted for the $D 1$ case with a strong normal shock forming slightly upstream of the after-body TE. Another visible flow feature is the local increase in static pressure near the vicinity of the vent nozzle exit. This generates an adverse pressure gradient that propagates upstream through the sub-sonic Boundary Layer (BL). This feature results in increased BL displacement thickness at the bypass nozzle throat, thus reducing nozzle mass flow. This effect can be noted in the behavior of $C_{D}^{\text {Bypass }}$ with increasing surface convexity presented in Fig. 5(d). The combined impact of both flow phenomena on $C_{V}^{\text {Overall }}$ can be clearly seen in Fig. 5(c) with $\Delta C_{V}^{\text {Overall }}$ approaching almost $-0.12 \%$ for the exhaust system shown in Fig. 4(f).

\subsection{Case specific after-body DSE and optimization}

3.2.1 DOE Having done a parametric analysis on the aerodynamic impact of after-body surface concavity, GEMINI was deployed to perform a holistic DSE with respect to the general effect of after-body curvature. Computational investigations were carried out for both datum exhaust designs, $D 1: l_{\text {vent }}^{\text {exit }}=0.85$ and D2: $l_{\text {vent }}^{\text {exit }}=0.25$, respectively. Each design space comprised only the design variables that controlled the after-body curvature terms shown in Fig. 2. During the DSE, the design variables were
Table 2. Design space bounds for after-body curvature parameters

\begin{tabular}{lccc}
\hline Design variable & Lower bound & Upper bound & Unit \\
\hline$D 1: l_{\text {vent }}^{\text {exit }}=0.85$ & & & \\
\hline$\Delta \theta_{\text {nozzle }}^{\text {exit }}$ & $-6(-2)$ & $6(2)$ & $\mathrm{deg}$ \\
$\Delta \theta_{\text {afterbody }}^{T E}$ & $-6(-2)$ & $6(2)$ & $\mathrm{deg}$ \\
$\kappa_{\text {nozzle }}$ & 2 & 60 & - \\
\hline$D 2: l_{\text {vent }}^{\text {exit }}=0.25$ & & & \\
\hline$\Delta \theta_{\text {vent }}^{\text {exit }}$ & $-6(-2)$ & $6(2)$ & $\mathrm{deg}$ \\
$\Delta \theta_{\text {vent }}^{T E}$ & $-3(-2)$ & $5(2)$ & $\mathrm{deg}$ \\
$\kappa_{\text {vent }}$ & 100 & 1000 & - \\
\hline
\end{tabular}

varied independently for each case, $D 1$ and $D 2$, respectively. Thus, each design space included a wide range of after-bodies including mixed convex-concave as well as concave-convex geometries (Fig. 3). The corresponding design space bounds are presented in Table 2 for cases $D 1$ and $D 2$, respectively.

The LHD method [32] was employed to disretize the design space of the $D 1$ and $D 2$ exhaust cases. An initial global design data-base containing 45 after-body geometries was compiled for each exhaust case using the CFD approach described and validated by the authors [7]. The initial design database covered a wide spectrum of over-turning angles that ranged between -6 and 6 degrees for $\Delta \theta_{\text {nozzle }}^{\text {exit }}, \Delta \theta_{\text {afterbody }}^{T E}$, and $\Delta \theta_{\text {vent }}^{\text {exit }}$. A range of -3 to 5 degrees was used for $\Delta \theta_{v e n t}^{T E}$ due to geometric constraints associated with the design of the core nozzle [7]. Subsequently, a second localized LHD DOE comprising another 45 samples was re-calculated for both $D 1$ and $D 2$ exhaust cases using a narrower set of design space bounds. The range of over-turning angles covered by the localized DOE was between -2 and 2 degrees for $\Delta \theta_{\text {nozzle }}^{\text {exit }}, \Delta \theta_{\text {afterbody }}^{T E}, \Delta \theta_{\text {vent }}^{T E}$, and $\Delta \theta_{\text {vent }}^{\text {exit }}$. The reduced design space bounds are documented in Table 2 within parentheses. The localized DOE results were subsequently super-imposed upon the initial global DOE for each exhaust case. This resulted in the compilation of a design database comprising a total of 90 geometries for each exhaust case, $D 1$ and $D 2$, respectively,

The purpose behind computing a localized LHD DOE was to derive a more densely populated exhaust design data-base around the conical design region. This was carried out to establish a refined representation of the exhaust system's aerodynamic response near the potentially optimum conical design region, as suggested by the parametric analysis findings shown in Fig. 5.

Figures 6(a) and (b) present scatter-plots of the obtained aerodynamic results in terms of $C_{V}^{\text {Overall }}$ and $C_{D}^{\text {Bypass }}$ for the $D 1$ and D2 exhaust data-bases, respectively. The estimated linear correlation coefficients, also known as Pearson's productmoments of correlation $N_{\text {Pearson }}$ [39], for the aerodynamic metrics of interest are also reported for each case. The linear correla- 


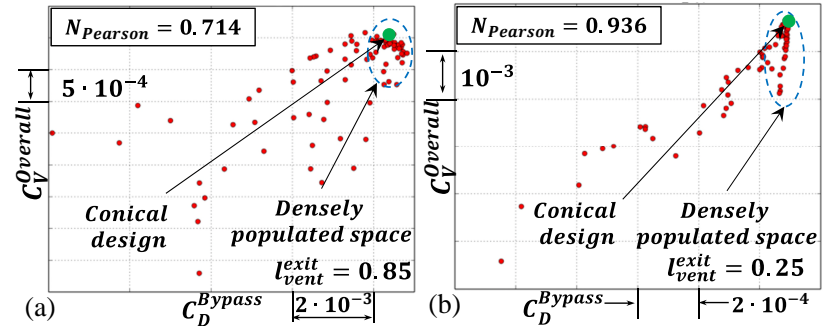

Figure 6. Case specific after-body DSE: Correlation between aerodynamic performance metrics $C_{V}^{\text {Overall }}$ and $C_{D}^{\text {Bypass }}$ : (a) $D 1$ exhaust case $l_{\text {vent }}^{\text {exit }}=0.85$, (b) D2 exhaust case $l_{\text {vent }}^{\text {exit }}=0.25$

tion coefficients indicate the amount and type of average dependency between two parameters and can range from -1 to 1 .

Figure 6(a) shows that regarding the $D 1$ case (Fig.4(a)), the range of metric variation observed is of the order of $0.4 \%$ and $0.9 \%$, for $C_{V}^{\text {Overall }}$ and $C_{D}^{\text {Bypass }}$, respectively [7]. This indicates that the parametric geometry definition used for the representation of the after-body implicitly also affects the design of the bypass nozzle. This is due to the strong dependency between the inner line angle at the bypass nozzle exit $\left(\Delta \theta_{\text {nozzle }}^{\text {exit }}\right.$, Fig. 2(b)) and the geometric con-di ratio which influences the aerodynamic performance of the nozzle (Fig. 4(c)). Indicatively, it is noted that the maximum con-di ratio for the design data-base shown in Fig. 6(a) reaches $0.5 \%$ for $\Delta \theta_{\text {nozzle }}^{\text {exit }}=6^{\circ}$. This trend also affects the aerodynamics of the overall exhaust system expressed through $C_{V}^{\text {Overall }}$. The associated value of $N_{\text {Pearson }}$ is 0.714 which indicates a notable positive correlation between the two metrics.

Figure 6(b) demonstrates that with respect to the $D 2$ exhaust case (Fig.4(b)), the variation range observed reaches $0.5 \%$ and $0.1 \%$ for $C_{V}^{\text {Overall }}$ and $C_{D}^{\text {Bypass }}$, respectively. The sensitivity computed for $C_{D}^{\text {Bypass }}$ is an order of magnitude below that observed for the $D 1$ case. This is due to the fact that there is no con-di ratio effect involved for this case (Fig. 2(c)). Thus, the bypass nozzle is fully-convergent $\left(R_{c o n-d i}=0\right)$ for all after-body designs investigated. The aerodynamic mechanism that induces changes in $C_{D}^{\text {Bypass }}$ is through the static pressure field at the vent nozzle exit (Fig. 4(f)). This behavior has been elaborated within section 3.1 of this paper. The computed value for $N_{\text {Pearson }}$ is close to 0.936 , indicating a strong correlation between $C_{V}^{O \text { verall }}$ and $C_{D}^{\text {Bypass }}$.

The aerodynamic metrics of the datum conical after-bodies (Figs. 4(a) and (b)) in terms of $C_{V}^{\text {Overall }}$ and $C_{D}^{\text {Bypass }}$, are annotated in Figs. 6(a) and (b) using green-colored dots. It can be observed that the DOE process has not identified a curved design which out-performs the conical datum geometries in terms of $C_{V}^{\text {Overall }}$. This indicates that, for the baseline exhaust cases investigated in this section, a simplified conical after-body shape may indeed be very close to optimum. However, to address this matter definitively, a systematic optimization procedure is required.

3.2.2 Surrogate Modeling Having computed a design data-base for each exhaust case, the obtained results were utilized to structure surrogate models (RSMs) that can approximate the response of the design space with sufficient accuracy in real-time. The approach employed in this paper was based on interpolation using Gaussian Processes Regression [33].

The classical LOO cross-validation method [8] was utilized to assess the quality of the structured RSMs. The method is applied as follows: An RSM is created for each of the DOE sample designs so that an RSM corresponds to a specific sample-point. The data used to structure each RSM include the entire range of DOE results with the exception of its corresponding samplepoint. Subsequently, the sample-point left-out of the data-base is compared against predictions made with its respective RSM. This process is repeated for all available DOE sample designs. The obtained RSM predictions are then cross-correlated against the original DOE results in terms of Pearson's index $N_{\text {Pearson }}$ along with the gradient of the associated linear regression line.

This process is illustrated in Figs. 7(a) and (b) for the $D 1$ and $D 2$ exhaust cases, respectively. It is noted that a perfectly linear correlation corresponds to $N_{\text {Pearson }}=1$ and a regression line gradient of $45^{\circ}$. It can be observed that the computed values of $N_{\text {Pearson }}$ when correlating RSM predictions with direct CFD results for $C_{V}^{\text {Overall }}$, are of the order of 0.987 and 0.970 for the $D 1$ and $D 2$ cases, respectively. The computed quality metrics indicate the excellent predictive accuracy of the structured RSMs.

3.2.3 Design optimization Having established confidence in the predictive capability of the structured RSMs, they can be used to guide the design optimization process. The objective is to identify whether application of after-body surface curvature can yield aerodynamic performance improvements relative to the case of a conical geometry. The NSGA-II method [35] was employed for all optimizations reported in this paper.

The optimization was restricted within the global design space bounds reported in Table 2 . The overall exhaust velocity coefficient $C_{V}^{\text {Overall }}$ was set as the objective function to be maximized. This is because, for the range of assumptions used in the present CFD approach, $C_{V}^{\text {Overall }}$ is the most representative and objective measure of aerodynamic performance [7]. The population size was set to be more than 33 times the number of variables for both cases. This resulted in a population size of 100 designs for each case. A convergence criterion of $10^{-18}$ was employed on the average consecutive mutations per generation.

Table 3 outlines the performance improvements achieved in $C_{V}^{\text {Overall }}$ and $F_{N}$ through the optimization, relative to the conical datum after-bodies shown in Figs. 4(a) and (b). Results are presented in the form of percentage differences relative to the equivalent conical designs. The associated metrics have been evaluated using CFD simulations. It can be noted that the performance improvements achieved in $C_{V}^{\text {Overall }}$ through using optimally designed curved after-bodies, are of the order of $1.02 \times 10^{-3}(\%)$ and $1.85 \times 10^{-3}(\%)$, for the $D 1$ and $D 2$ exhausts, respectively. It is noted that the quoted performance deltas are insignificant and

I. Goulos et al. 

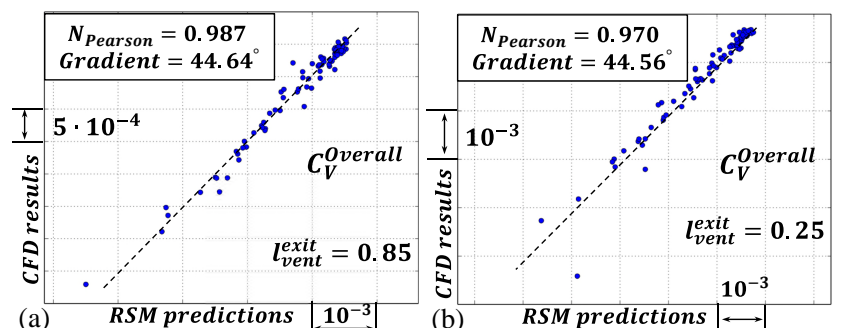

Figure 7. LOO cross-validation applied to the RSMs for $C_{V}^{O \text { verall }}$ : (a) $D 1$ exhaust case $l_{\text {vent }}^{\text {exit }}=0.85$, (b) $D 2$ exhaust case $l_{\text {vent }}^{\text {exit }}=0.25$

likely within the uncertainty of the employed CFD method [7]. However, it is also emphasized that the behavior of the design space observed in Fig. 6, in combination with the parametric analysis results shown in Fig. 5, showcase that minor departures from a conical after-body geometry can lead to a notable reduction in $C_{V}^{\text {Overall }}$. This sensitivity is particularly evident for exhaust system designs where the air-flow vent is placed near the vicinity of the bypass nozzle exit, as shown in Fig. 5(c).

Table 3. Exhaust case specific optimization results

\begin{tabular}{lcc}
\hline Performance metrics & Optimized (curved) & Unit \\
\hline$D 1: l_{\text {vent }}^{\text {exit }}=0.85$ & & \\
\hline$\Delta C_{V}^{\text {Overall }}(\%)$ & $1.02 \times 10^{-3}$ & $(\%)$ \\
$\Delta F_{N}(\%)$ & $4.17 \times 10^{-3}$ & $(\%)$ \\
\hline$D 2: l_{\text {vent }}^{\text {exit }}=0.25$ & & \\
\hline$\Delta C_{V}^{\text {Overall }}(\%)$ & $1.85 \times 10^{-3}$ & $(\%)$ \\
$\Delta F_{N}(\%)$ & $7.56 \times 10^{-3}$ & $(\%)$ \\
\hline
\end{tabular}

Figure 8 compares the aerodynamic behavior of the optimized curved after-bodies with their respective conical baselines. It can be noticed that the optimized after-body designs are geometrically very similar to the datum exhausts. With respect to the $D 1$ case, a slightly convex design solution has been obtained with $\Delta \theta_{\text {nozzle }}^{\text {exit }}=-1.33^{\circ}$ and $\Delta \theta_{\text {nozzle }}^{T E}=0.37^{\circ}$. A concave geometry has been favored for the $D 2$ exhaust with $\Delta \theta_{\text {vent }}^{\text {exit }}=0.29^{\circ}$ and $\Delta \theta_{\text {vent }}^{T E}=-0.40^{\circ}$. The selection of different design philosophies is due to the different flow mechanisms that dominate the aerodynamics of the exhaust system for each case.

The obtained sets of optimum design variables are very close to those of a conical geometry whereby $\Delta \theta_{\text {nozzle } / \text { vent }}^{\text {exit }}=0^{\circ}$ and $\Delta \theta_{\text {nozzle } / \text { vent }}^{\text {exi }}=0^{\circ}$. However, Figs. 8(c) and (d) illustrate that, due to the high sensitivity of the transonic flow topology on the core after-body to surface curvature variations, certain adverse flow features begin to manifest. For the slightly convex $D 1$ after-body shown in Fig. 8(c), the existence of a weak shock can be observed aft of the bypass nozzle exit which is absent in the flow

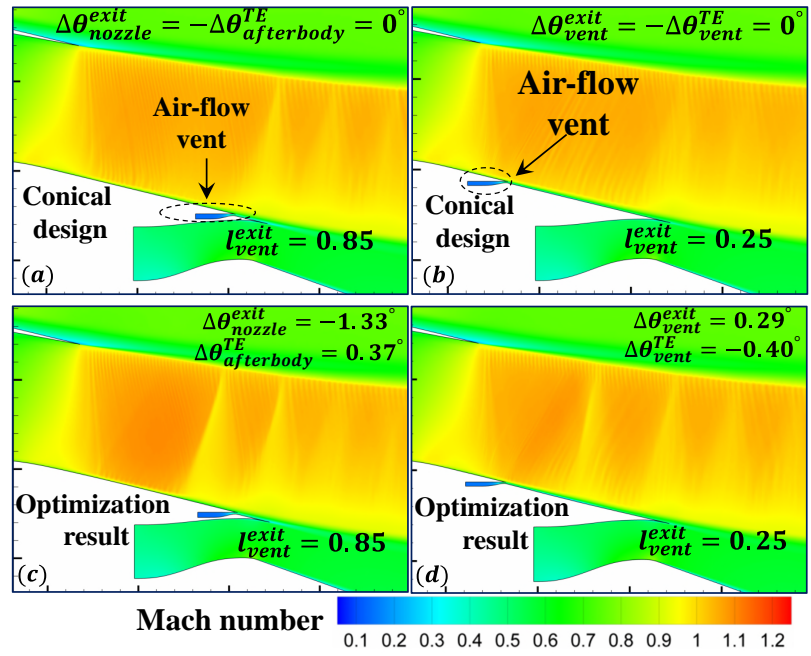

Figure 8. Comparison of core after-body aerodynamic behavior: (a) Datum conical $D 1$ after-body, (b) Datum conical $D 2$ after-body, (c) Optimized curved $D 1$ after-body, (d) Optimized curved $D 2$ after-body

corresponding to the conical design shown in Fig. 8(a). A similar behavior, though less distinct, can be noticed for the optimum curved after-body corresponding to the $D 2$ case (Fig. 8(d)).

Since the detected adverse flow features are relatively weak, their impact on $C_{V}^{\text {Overall }}$ is unlikely to be larger compared to the numerical uncertainty implicit in the CFD flow-solutions [7]. However, the aforementioned features are not present in the aerodynamic behavior noted for the conical after-body geometries (Figs. 8(a) and (b)). This indicates that, although the estimated values of $C_{V}^{\text {Overall }}$ for the optimized curved and conical afterbodies are almost identical, a conical geometry is inherently and physically more favorable and robust from an aerodynamic point of view. Hence, it can be concluded that with respect to the investigated exhaust cases, application of after-body surface curvature does not result in an aerodynamic performance improvement relative to a conical design. A conical after-body appears to be the optimum design solution from an aerodynamic stand-point.

\subsection{Global DSE and optimization}

The optimizations reported in the previous section were carried out for two representative datum exhausts, the $D 1$ and the $D 2$ design cases. These were established by fixing the key geometric parameters that uniquely define a baseline conical afterbody shape. These include the after-body TE position, the airflow vent location, and the vent exit area. The effect of surface curvature was then subsequently applied on the conical datum after-bodies without accounting for the influence of the underlying general design parameters. Hence, the conclusions reached in the previous section are strictly applicable to the specific baseline designs investigated. Within this section, an effort has been made to arrive at a general conclusion regarding the influence of after-body curvature that is applicable throughout the entire de- 


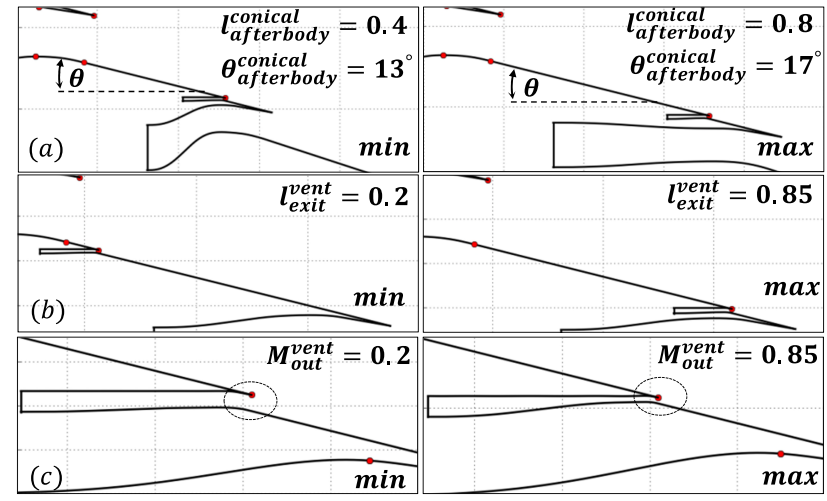

Figure 9. Design space bounds employed for the general core afterbody design variables: (a) $l_{\text {afterbody }}^{\text {conical }}$ and $\theta_{\text {afterbody }}^{\text {conical }}$, (b) $l_{\text {vent }}^{\text {exit }}$, (c) $M_{\text {out }}^{\text {vent }}$

sign space including all possible after-body TE locations, as well as air-flow vent positions and exit area requirements.

Figure 9 depicts the bounded design variables employed to establish a parametric representation of a conical after-body geometry. The position of the after-body TE is specified through the designation of an equivalent normalized length $l_{\text {afterbody }}^{\text {conical }}=$ $L_{\text {conical }}$ $\frac{L_{\text {afterbody }}^{\text {conical }}}{R_{\text {fan }}}$ and half-cone angle $\theta_{\text {afterbody }}^{\text {conical }}($ Fig. 9(a)). The air-flow vent design variables include its axial location on the after-body $l_{\text {vent }}^{\text {exit }}=\frac{L_{\text {vent }}^{\text {exit }}}{L_{\text {afterbody }}^{\text {conical }}}($ Fig. 9(b)) and the vent exit area. The latter parameter is implicitly derived through specifying the flow Mach number $M_{\text {out }}^{\text {vent }}$ at the vent exit (Fig. 9(c)). The impact of $l_{\text {afterbody }}^{\text {conical }}, \theta_{\text {afterbody }}^{\text {conical }}, l_{\text {vent }}^{\text {exit }}$, and $M_{\text {out }}^{\text {vent }}$ on the aerodynamic behavior of separate-jet exhausts with conical after-bodies has been previously investigated by Goulos et al. [7,8].

The conical exhaust design parameters illustrated in Fig. 9 and the after-body curvature variables described in Table 2 and depicted in Fig. 2, were combined to establish a holistic representation of the global exhaust design space. The global design space was subsequently discretized with the deployment of the LHD DOE method [32]. A data-base containing 500 exhaust geometries was generated using GEMINI's CFD approach, thus establishing densely populated aerodynamic design space. The obtained DOE results were then utilized to structure surrogate models using the Kriging method as described in sub-section 3.2.2 of this paper. The LOO cross-validation approach [8] was employed to assess the predictive accuracy of the RSMs. The computed values of $N_{\text {Pearson }}$ and regression gradient for cross-correlating RSM predictions with CFD results in terms of $C_{V}^{\text {Overall }}$, were of the order of 0.972 and $44.70^{\circ}$, respectively.

The NSGA-II method [35] was subsequently deployed to perform a holistic analysis on the aerodynamic impact of afterbody curvature. Initially, a global optimization was carried out whereby all the available DOFs were treated as variables. These included the underlying conical after-body parameters (Fig. 9) as
Table 4. Global exhaust design optimization results

\begin{tabular}{lccc}
\hline Variables/metrics & Opt. (curved) & Opt.(conical) & Unit \\
\hline$\Delta C_{V}^{\text {Overall }}(\%)$ & $8.05 \times 10^{-3}$ & $2.80 \times 10^{-3}$ & $(\%)$ \\
$\Delta F_{N}(\%)$ & $3.29 \times 10^{-2}$ & $1.14 \times 10^{-2}$ & $(\%)$ \\
\hline
\end{tabular}

well as the associated curvature terms (Fig. 2 and Table 2). Subsequently, a bounded optimization was performed whereby the curvature variables were fixed to match values corresponding to conical geometries so that: $\Delta \theta_{\text {nozzle } / \text { vent }}^{\text {exit }}=0^{\circ}, \Delta \theta_{\text {afterbody } / \text { vent }}^{T E}=$ $0^{\circ}$, and $\kappa_{\text {vent }}=\max$. However, the underlying conical after-body parameters were allowed to vary within their original boundaries (Fig. 9). This approach bounded the optimization within the design space parts that consisted of strictly conical after-bodies. Thus, by comparing the outcome of each optimization, a general conclusion can be reached as to whether inclusion of after-body curvature can open-up new territories in the multi-dimensional design space leading to better aerodynamic performance.

Table 4 reports the aerodynamic performance improvements achieved in $C_{V}^{O \text { verall }}$ and $F_{N}$ through the described optimization processes, relative to the conical $D 2$ datum after-body shown in Fig. 4(b). Results are reported for the global optimization including the influence of after-body curvature (curved), as well as for the bounded case which was constrained to strictly conical geometries. Once again, it can be observed that the predicted performance improvements in terms of $C_{V}^{\text {Overall }}$ are insignificant. These are of the order of $8.05 \times 10^{-3}(\%)$ and $2.80 \times 10^{-3}(\%)$ for the "curved" and "conical" after-body cases, respectively. The flow solutions corresponding to the optimized after-body geometries are illustrated in Figs. 10(a) and (b) for the "curved" and "conical" optimum exhaust geometries, respectively.

Figure 10 illustrates that both after-body geometries exhibit favorable aerodynamic characteristics. The observed transonic flow effects are relatively benign and limited to clearly-discerned patterns of weak oblique shock and expansion waves. With respect to the former case, Fig. 10(a) shows that the amount of curvature applied on the optimized after-body is limited. Specifically, a relatively small amount of surface concavity has been employed with respect to both fore and aft vent nozzle exit afterbody sections. Considering the upstream part, the optimum curved aeroline shape is designed with: $\Delta \theta_{\text {nozzle }}^{\text {exit }}=0.27^{\circ}$ and $\Delta \theta_{\text {nozzle }}^{\text {exit }}=-0.21^{\circ}$, whilst for the downstream part it applies that: $\Delta \theta_{\text {vent }}^{\text {exit }}=0.75^{\circ}$ and $\Delta \theta_{\text {nozzle }}^{\text {exit }}=-0.02^{\circ}$. Thus, for the low-specificthrust engine investigated in this work, the optimum curved afterbody shape is geometrically similar to a conical design.

With regards to the latter case, the optimization has arrived to a design that is very similar to the original conical datum afterbody $D 2$ shown in Fig. 4(b). This due to the fact that, the datum exhaust geometry was pre-optimized assuming a conical afterbody representation [8] prior to performing the optimizations reported in this work. This is also evident from the fact that the 


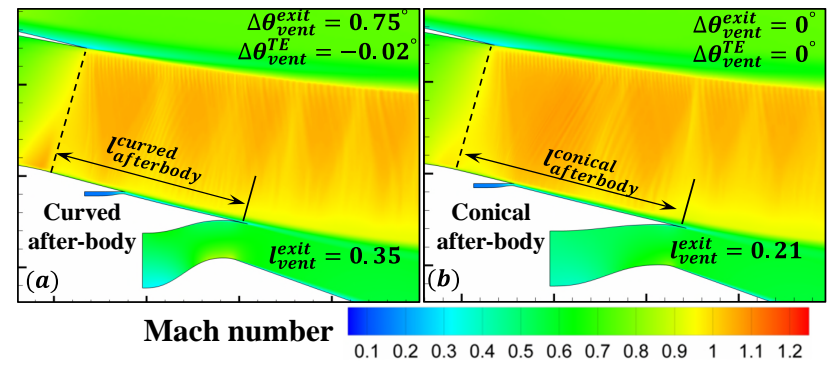

Figure 10. Aerodynamic behavior of globally optimized after-body designs: (a) Geometry optimized with inclusion of after-body surface curvature, (b) Geometry optimized with conical after-body

aerodynamic performance of the optimum conical design is practically identical to that of the datum exhaust since the estimated value for $\Delta C_{V}^{O \text { verall }}$ is $2.80 \times 10^{-3}(\%)$. Furthermore, the improvement obtained in $C_{V}^{O v e r a l l}$ when the associated after-body curvature terms are included in the design space, is of the order of $5.2 \times 10^{-3}(\%)$ relative to the optimized conical design.

The reported differences in performance are essentially insignificant and within the numerical uncertainty implicit in the applied CFD approach [7]. Thus, it can be concluded that, within the context of separate-jet exhaust design, inclusion of nozzle after-body surface curvature does not improve the aerodynamic performance of the exhaust system. A conical after-body appears to be the globally optimum aerodynamic solution for lowspecific thrust aero-engines with separate-jet exhausts.

Furthermore, a closer inspection of the aerodynamic results presented in Fig. 10 reveals that the optimized curved after-body geometry shown in Fig. 10(a) is approximately 15\% shorter compared to the optimum conical after-body shape of Fig. 10(b). In other words, inclusion of surface curvature in the optimization process has enabled the design of a shorter after-body without incurring any aerodynamic performance penalty. Thus, it can be concluded that, although the inclusion of after-body curvature has not directly lead to aerodynamic improvements, it has resulted in a specific exhaust design with reduced after-body length whilst maintaining optimal aerodynamic performance.

\section{Conclusions}

This paper has conducted an extensive numerical investigation on the aerodynamic behavior of civil aero-engine exhaust systems with emphasis on the design of the bypass nozzle after-body. A mathematical approach has been developed based on CST functions for the parametric representation of aftnozzle-exit components such as after-bodies, air-flow vents, and plugs. The developed method has been implemented into an integrated tool for the aerodynamic analysis of exhaust systems. A computationally-efficient DSE and optimization strategy has been adapted comprising methods for DOE, RSM, and global optimization. The developed framework has been deployed to explore the aerodynamic design space associated with the applica- tion of after-body surface curvature for a VHBR turbofan engine with separate-jet exhausts. A set of optimum exhaust designs have been derived including the influence of after-body surface curvature as well as assuming a simplified conical representation.

It has been demonstrated that the position of the air-flow vent on the exhaust after-body is key in determining the underlying transonic flow mechanisms that manifest aft of the bypass nozzle exit. The aerodynamic impact of after-body surface curvature has been found to be dependent on the axial location of the vent exhaust nozzle. The results suggest that with respect to the investigated exhaust cases, application of after-body curvature does not result in aerodynamic performance improvements relative to simplified conical designs. However, it has been shown that inclusion of surface curvature can enable the design of shorter after-bodies without incurring any aerodynamic performance penalties. Thus, although inclusion of after-body curvature does not lead to performance improvements, it can allow designers to reduce after-body length whilst maintaining optimal aerodynamic performance. The developed tool adds to the existing tool-set of enabling technologies aiming towards the conceptual design of the next generation of civil large aero-engines.

\section{Acknowledgments}

This project was co-funded by Innovate UK.

\section{References}

[1] Guha, A., "Optimum Fan Pressure Ratio for Bypass Engines with Separate or Mixed Exhaust Streams," Journal of Propulsion and Power, Vol. 17, (5), September-October 2001 2001, pp. 1117-1122.

[2] Walsh, P. and Fletcher, P., Gas Turbine Performance Engineering, Blackwell Publishing, 2004.

[3] Keith, B. D., Uenishi, K., and Dietrich, D. A., "CFD-Based ThreeDimensional Turbofan Exhaust Nozzle Analysis System," Journal of Propulsion and Power, Vol. 9, (6), November-December 1993, pp. 840 846.

[4] Dusa, D., Lahti, D., and Berry, D., "Investigation of Subsonic Nacelle Performance Improvement Concept," 18th Joint Propulsion Conference, Cleveland, OH, U.S.A, June 21-23 1982.

[5] Wilson, E. A., Adler, D., and Bar-Yoseph, P., "Nozzle Performance Modeling," AIAA Journal, Vol. 40, (7), July 2002, pp. 1331-1338.

[6] Bussman, W. and White, J., "Explicit Equation for Flow Through American Society of Mechanical Engineers Nozzle Meters," AIAA Journal, Vol. Vol. 36, (9), September 1998, pp. 1744-1746.

[7] Goulos, I., Stankowski, T., Otter, J., MacManus, D., Grech, N., and Sheaf, C., "Aerodynamic Design of Separate-Jet Exhausts for Future Civil AeroEngine, Part 1: Parametric Geometry Definition and CFD Approach," ASME J. Eng. Gas Turbines and Power, Vol. 138, (8), August 2016, pp. 081201.

[8] Goulos, I., Otter, J., Stankowski, T., MacManus, D., Grech, N., and Sheaf, C., "Aerodynamic Design of Separate-Jet Exhausts for Future Civil AeroEngines, Part 2: Surrogate Modeling and Optimization," ASME J. Eng. Gas Turbines and Power, Vol. 138, (8), August 2016, pp. 081202.

[9] Heath, C. M., Gray, J. S., Park, M. A., Nielsen, E. J., and Carlson, J.R., "Aerodynamic Shape Optimization of a Dual-Stream Supersonic Plug Nozzle," SciTech 2015, No. GRC-E-DAA-TN19528, Reston, VA, United States, 5-9 January 2015.

[10] Clemen, C., Albrecht, P., and Herzog, S., "Systematic Optimisation of a Turbofan Bypass Duct System,” ASME Turbo Expo 2012: Turbine Tech- 
nical Conference and Exposition, No. GT2012-68276, Copenhagen, Denmark, June 11-15 2012.

[11] Qiu, S., Song, W. B., and Liu, H., "Shape Optimization of a General Bypass Duct for Tone Noise Reduction Using Continuous Adjoint Method," IMECHE Journal of Mechanical Engineering Science, Vol. 228, (1), January 2014, pp. 119-134.

[12] Peace, A. J., "A Method for Calculating Afterbody Flows," Journal of Propulsion and Power, Vol. 13, (4), July-August 1987, pp. 357-364.

[13] Bouter, M. Z., Graham, D. H., Jager, M., and Totland, E., "Subsonic Base and Boat-tail Pressure Drag of Cylindrical Bodies with Circular-Arc Boattails and a Central Propulsive Jet," ESDU, ESDU-02012, July 2005.

[14] Bouter, M. Z., Graham, D. H., Jager, M., and Totland, E., "Subsonic Pressure Drag of Boat-tails with Negligible Annular Base Area in the Presence of a Central Propulsive Jet," ESDU, ESDU-01012, November 2001.

[15] Compton, W. B., "An Experimental Study of Jet Exhaust Simulation," National Aeronautics and Space Administration, NASA-TM X-71975, Langley Research Center, Hampton, Virginia, 23665, June 1974.

[16] Compton, W. B., "Effects of Jet Exhaust Gas Properties on Exhaust Simulation and Afterbody Drag," National Aeronautics and Space Administration, NASA-TR-R-444, Langley Research Center, Hampton, Va, 23365, October 1975.

[17] Compton, W. B., "Effect on Base Drag of Recessing the Bases of Conical Afterbodies at Subsonic and Transonic Speeds," National Aeronautics and Space Administration, NASA-TN-D-4821, Langley Research Center, Langley Station, Hampton, VA, October 1968.

[18] Compton, W. B. and Runckel, J. F., "Jet Effects on the Boattail Axial Force of Conical Afterbodies at Subsonic and Transonic Speeds," National Aeronautics and Space Administration, NASA-TM-X-1960, Langley Research Center, Langley Station, Hampton, Va, February 1970.

[19] Jameson, A., Schmidt, W., and Turkel, E., "Numerical Solutions of the Euler Equations by Finite Volume Methods using Runge-Kutta Time Stepping Schemes," No. AIAA Paper 81-1259, June 1981.

[20] Williams, B. R., "The Prediction of Separate Flow Using a Viscous/Inviscid Interaction Method," Aeronautical Journal, Vol. 89, May 1985, pp. 185197.

[21] Kulfan, B. M., "Recent Extensions and Applications of the 'CST' Universal Parametric Geometry Representation Method," Aeronautical Journal, Vol. 114, (1153), March 2010, pp. 157-176.

[22] Kulfan, B. M., "Universal Parametric Geometry Representation Method," Journal of Aircraft, Vol. 45, (1), January-February 2008, pp. 142-158.

[23] Zhu, F. and Qin, N., "Intuitive Class/Shape Function Parameterization for Airfoils," AIAA Journal, Vol. 52, (1), January 2014, pp. 17-25.

[24] Macmillan, W. L., Development of a Module Type Computer Program for the Calculation of Gas Turbine Off Design Performance, Ph.D. thesis, Department of Power and Propulsion, Cranfield University, 1974.

[25] Ansys Inc., 275 Technology Drive, Canonsburg, PA 15317, ANSYS ICEM CFD Tutorial Manual.

[26] Ansys Inc., 275 Technology Drive, Canonsburg, PA 15317, ANSYS FLUENT User's Guide.

[27] Pachidis, V., Pilidis, P., Marinai, L., and Templalexis, I., "Towards a full two dimensional gas turbine performance simulator," Aeronautical Journal, Vol. 111, (1121), 2007, pp. 433-442.

[28] Wilcox, D. C., "Comparison of Two-Equation Turbulence Models for Boundary Layers with Pressure Gradient," AIAA Journal, Vol. 31, (8), August 1993, pp. 1414-1421.

[29] Bardina, J. E., Huang, P. G., and Coakley, T. J., "Turbulence Modeling Validation, Testing, and Development," National Aeronautics and Space Administration, NASA TM-110446, Moffet Field, CA, US, April 1997.

[30] Radovanovi, M., Nanopoulos, A., and Ivanovic, M., "Hubs in Space: Popular Nearest Neighbors in High-Dimensional Data," Journal of Machine Learning Research, Vol. 11, October 2010, pp. 2487-2531.

[31] Gao, Y., Wu, Y., and Xia, J., "Automatic Differentiation Based Discrete
Adjoint Method for Aerodynamic Design Optimization on Unstructured Meshes," Chinese Journal of Aeronautics, Vol. 30, (2), February 2017, pp. 611-627.

[32] Olsson, A., Sandberg, G., and Dahlblom, O., "On Latin hypercube sampling for structural reliability analysis," Structural Safety, Vol. 25, No. 1, 2003, pp. $47-68$.

[33] Bayraktar, H. and Turalioglu, F., "A Kriging-based approach for locating a sampling site in the assessment of air quality," Stochastic Environmental Research and Risk Assessment, Vol. 19, 2005, pp. 301-305.

[34] Kohavi, R., "A Study of Cross-Validation and Bootstrap for Accuracy Estimation and Model Selection," Proceedings of the Fourteenth International Joint Conference on Artificial Intelligence, Vol. 2, 1995, p. 11371143.

[35] Deb, K., Pratap, A., Agarwal, S., and Meyarivan, T., "A Fast and Elitist Multiobjective Genetic Algorithm: NSGA-II," EEE Transactions on Evolutionary Computation, Vol. 6, (2), April 2002, pp. 182 - 197.

[36] Guynn, M. D., Berton, J. J., Fisher, K. L., Haller, W. J., Thurman, D. R., and Tong, M. T., "Refined Exploration of Turbofan Design Options for an Advanced Single-Aisle Transport," National Aeronautics and Space Administration, TM2011-216883, Army Research Laboratory, Cleveland, Ohio, January 2011

[37] Haselback, F., Newby, A., and Parker, R., "Next Generation of Large Civil Aicraft Engines - Concepts and Technologies," European Turbomachinery Conference, 23-27 March 2015, Madrid, Spain, 2015.

[38] Bijewitz, J., Seitz, A., and Hornung, M., "Architectural Comparison of Advanced Ultra-High Bypass Ratio Turbofans for Medium to Long Range Application,” Deutscher Luft- und Raumfahrtkongress, No. DocumentID: 340105, 16-18 September 2014.

[39] Hotelling, H., "New Light in the Correlation Coefficient and its Transforms," Journal of the Royal Statistical Society, Vol. 15, (2), No. 193-232, 1953. 
2017-09-11

Civil turbofan engine exhaust

aerodynamics: impact of bypass nozzle after-body design

\section{Goulos, loannis}

\section{Elsevier}

Ioannis Goulos, Tomasz Stankowski, David MacManus, Philip Woodrow, Christopher Sheaf, Civil turbofan engine exhaust aerodynamics: Impact of bypass nozzle after-body design, Aerospace Science and Technology, Volume 73, February 2018, Pages 85-95

http://dx.doi.org/10.1016/j.ast.2017.09.002

Downloaded from Cranfield Library Services E-Repository 